\title{
Quick isolation and characterization for the confirmation of a novel Bacillus thuringiensis strains from chicken manure samples
}

\author{
Suguna Muniady ${ }^{1}$, Xavier Rathinam ${ }^{1}$ and Sreeramanan Subramaniam ${ }^{2 \star}$ \\ ${ }^{1}$ AIMST University, Bukit Air Nasi, Jalan Bedong, 08100, Kedah, Malaysia. \\ ${ }^{2}$ School of Biological Sciences, Universiti Sains Malaysia, Gelugor, 11800 Penang, Malaysia.
}

Accepted 25 June, 2011

\begin{abstract}
Bacillus thuringiensis (Berliner) (Bt) based pesticides has become the greatest successes among the microbial pesticides. This research was focused on the isolation and characterization of $\mathrm{Bt}$ from chicken manure samples as a comprehensive effort to contribute to the establishment of native $\mathrm{Bt}$ strains from various types of habitats in Malaysia. Initially, selection was done mainly based on colony morphology, Gram staining and phase contrast microscopy. Total of 85 colonies were identified and isolated based on colony morphology, in which off-white, matte and creamy appearance showed the characteristics of the genus Bacillus. The number reduced to 35 colonies after Gram staining was done. Subsequently, total of 8 isolates were confirmed to be $B$. thuringiensis after Coomassie Brilliant Blue staining was carried out. The presence of $B$. thuringiensis strain was confirmed when a blue cap-like structure and a darkly stained oval structure, insecticidal crystal proteins (ICP) appeared in the sporulation phase. An isolate was chosen out of the 8 isolates in order to generate the growth curve of $B$. thuringiensis bacteria. The similarity of the aspects above confirms that the selected isolate was a $\mathrm{Bt}$ strain. Isolates were further characterized by SDS-PAGE analysis to determine the molecular masses of the Bt proteins. These isolates produced two major ranges of polypeptides, the Cry protein which corresponds to a range of $70-150 \mathrm{kDa}$ and the Cyt protein profile which corresponds to the range of 18$40 \mathrm{kDa}$. The protein profile obtained correlates the strains to the typical Bt strain. A total of 6 isolate yielded SDS-PAGE products that demonstrated major protein bands of approximately 135kDa and $140 \mathrm{kDa}$, possibly encoded by the genes cryl and crylV, respectively.
\end{abstract}

Key words: Bacillus thuringiensis, chicken manure, protein analysis.

\section{INTRODUCTION}

Bacillus thuringiensis (Bt) is a naturally occurring bacterium common in soils throughout the world and belongs to the group Bacillus cereus sensu lato (Huang et al., 2001). Bt is from the family of Bacillaceae which encompasses two genus divisions, namely Clostridium and Bacillus. Hence, Bt is a ubiquitous bacteria with Gram-positive, spore-forming, rod-shaped in nature and is approximately $1 \mu \mathrm{m}$ in width and $5 \mu \mathrm{m}$ in length (Konecka et al., 2006).

${ }^{\star}$ Corresponding author. E-mail: sreeramanan@usm.my. Tel: 6016-4141109. Fax: 604-6565125
Generally, Bt strains are categorized according to the cry gene group (Moraga et al., 2004). Cry proteins have been classified according to their insect specificity and nucleotide sequence (Konecka et al., 2006; Ghelardi et al., 2007). Formulated and sporulated cultures of $B$. thuringiensis are widely used as foliar sprays as a part of integrated pest management strategies against insect pests of agricultural crops (Schnepf et al., 1998; Lacey et al., 2001) without presenting any harmful threats to the environment and human beings (Crickmore, 2006). Most of the insecticidal activity of $\mathrm{Bt}$ is due to intracellular crystal inclusions produced during the process of sporulation. These parasporal crystals are comprised of one or more related ICPs encoded by cry (crystal) and 
cyt (cytolytic) genes located mainly on plasmids. Both the cry and cyt genes are highly diverse with more than 30 types of Cry proteins and 8 types of Cyt proteins have been described, and over 100 genes have been cloned and sequenced (Schnepf et al., 1998; Konecka et al., 2006; Ghelardi et al., 2007). Target insect specificity is determined mainly by these insecticidal crystal proteins (ICPs). These two proteins act together to affect the larvicidal activity of the parasporal crystals (Ghelardi et al., 2007).

Upon ingestion by a susceptible insect, the toxic crystals become solubilized in the gut (Crickmore 2006). The $\delta$-endotoxins become activated in the gut of the susceptible insects. At this stage, the environmental condition of the insects gut are very important, whereby the $\delta$-endotoxins dissolve in the high $\mathrm{pH}$ (alkaline condition) of the insects' gut and become active (Aronson and Shai, 2001). The different habitats contained novel Bt strains awaiting discovery which has a toxic effect on a target insect group. In the present study, we have isolated and characterize $B$. thuringiensis from chicken manure samples from four different locations using a quick isolation protocol. The main reason for obtaining samples from different locations is to broaden the probability of getting $B$. thuringiensis strains in chicken manure.

\section{MATERIALS AND METHODS}

\section{Sample collection and preparation}

Manure samples were collected from four (4) different chicken farms located at Semeling, Alor Star, Kulim, and Alor Gajah in Malaysia. Total of fifty-five pooled samples of dried poultry manure material, each weighing about 20 to $30 \mathrm{~g}$, were collected using a clean spatula. The top most layer of the manure heap, about $1.0 \mathrm{~cm}$, was removed and the manure residing beneath this layer was collected. The samples were immediately placed into sterile plastic bags ( $6.0 \times 9.5$ inches). The clean spatula and sterile plastic bags were used mainly to avoid cross contamination with environmental material. Additionally, the samples were free of soil contamination. Each manure sample were then labelled and stored at ambient temperature for further studies.

\section{Processing of manure samples}

Approximately $5 \mathrm{~g}$ from each of the manure samples were weighed and suspended in $100 \mathrm{ml}$ of sterile distilled water in $250 \mathrm{ml}$ conical flasks. The conical flasks were then covered using cotton plug to avoid cross contamination with external sources. The suspension was incubated in an orbital shaker set at $250 \mathrm{rpm}$ for $5 \mathrm{~h}$ at ambient temperature. This procedure was done to ensure proper soil-water homogenization and also to ascertain that the microbes that are attached to the manure particles are thoroughly dispensed in the sterile distilled water. Using a pipette, $1 \mathrm{ml}$ aliquot from each of the samples were removed and transferred to separate pre-warmed 5 $\mathrm{ml}$ boiling tubes. The aliquots were then given heat-shock treatments at $80^{\circ} \mathrm{C}$ for $15 \mathrm{~min}$ in a water bath to kill all the vegetative and non-spore forming cells. After giving the heat-shock treatments, the suspensions were vortex and five-fold serial dilutions were done. In each of the serial dilution step, $100 \mu \mathrm{l}$ aliquot was added to 900 $\mu \mathrm{l}$ of sterile distilled water. The suspensions were vortex in between of the serial dilutions. Thereafter, subsequent plating of $20 \mu \mathrm{l}$ of aliquots of each of the serial dilutions for each samples, ranging from $10^{-3}$ to $10^{-5}$ were done on nutrient agar plates using spread plate technique and subjected to incubation at $30^{\circ} \mathrm{C}$ for 24 to $48 \mathrm{~h}$. The plates were examined for colonies having Bacillus-like morphology, at every $10 \mathrm{~h}$. The potential Bacillus colonies were further characterized using morphological and biochemical characterizations.

\section{Morphological characterization}

The colonies which had characteristics very similar to Bacillus group, which is white to off-white in colour, opaque, slightly raised elevation, and regular outlined colonies were selected. In total 85 Bacillus-like colonies were identified and sub-cultured onto fresh Nutrient Agar plates and were labelled.

\section{Gram staining}

Gram staining was done to eliminate Gram negative bacteria and select only the rod-shaped, Gram positive ones. First, samples are smeared on clean glass slides, followed by heat-fixing and airdrying. The smears were then stained with the basic dye crystal violet, the primary stain, followed by treatment with iodine solution, which functions as a mordant. The smears were then decolourized using acetone. Finally, the smears were counterstained with the basic dye, Safranin, and air-dried. The smeared slides were then observed under the microscope. The differential aspect of the Gram stain can be shown as Gram positive bacteria retained crystal violet, leaving in dark purple and Gram negative bacteria lose their crystal violet and stain pink instead. In total, 35 Gram positive with rod shaped colonies were identified.

\section{Phase contrast microscopy}

All the 35 colonies that were Gram positive and rod in shape were examined for the presence of parasporal inclusion by phasecontrast microscopy. First, the colony samples were inoculated into sterilized $100 \mathrm{ml}$ conical flasks containing $50 \mathrm{ml}$ Nutrient Broth (NB). The cultures were then incubated at room temperature on an orbital shaker with $250 \mathrm{rpm}$ agitation for $90 \mathrm{~h}$. This was done so as to allow sporulation of the isolated bacterial cells. Wet mount slides were prepared from the inoculated cultures after $50 \mathrm{~h}$ of incubation to visualize the vegetative phase morphology of the isolates under the phase contrast microscope. Additionally, wet mounts were also prepared after $90 \mathrm{~h}$ to visualize the formation of the endospore and the parasporal bodies, characteristics of $B$. thuringiensis (Rampersad et al., 2001). A total of 8 samples were identified as having parasporal bodies. However, phase contrast microscopy could not clearly distinguish the capped spores, and thus they were further subjected to characterization using Coomassie Brilliant Blue staining technique.

\section{Coomassie brilliant blue (CBB) staining}

The CBB stain allows high throughput evaluation of the bacterial colonies for the presence of crystals (Rampersad and Ammons, 2005) as it increases resolution over phase contrast microscope (Olympus BX50 fitted with a JVC K-F55B colour video camera and analysis Document Version 3.1 image analysis system). The characterization using CBB stain was done at two phases of the Bacillus growth cycle, at the sporulation phase and at the autolysis phase. The isolates that were selected earlier using the Gramstaining technique were first inoculated into sterilized $100 \mathrm{ml}$ conical 
flasks containing $50 \mathrm{ml}$ Nutrient Broth. The samples were then incubated in an orbital shaker for 90 and $110 \mathrm{~h}$ at room temperature with $250 \mathrm{rpm}$ agitation. Incubation for $90 \mathrm{~h}$ allows sporulation process to occur whereas $110 \mathrm{~h}$ incubation allows complete autolysis to take place.

An aliquot of a sporulated colony was transferred onto clean glass slides followed by heat fixing and air-drying. The step was done for each of the samples at both the sporulation and autolysis phases. Thereafter, the slides were then stained using $0.133 \%$ Coomassie Blue stain in $50 \%$ acetic acid (Rampersad et al., 2002) for about $1 \mathrm{~min}$ and then rinsed off using the prepared destaining solution. The slides were then dried and observed under phase contrast microscope to visualize the formation of toxin-containing parasporal bodies and the spores. The morphological characters of the crystals were also examined, whether the shapes of the crystals were bipyramidal, cuboidal, oval or irregularly shaped. In total, all the 8 samples which were identified as having the parasporal bodies had stained dark blue and the presence of the endospore can be clearly detected. These samples were classified as $B$. thuringiensis (Bernhard et al., 1997) and were subjected to characterization using SDS-PAGE analysis.

\section{Growth curve analysis}

A Bt isolate was chosen in order to generate the growth curve. This was done to confirm that the $\mathrm{Bt}$ isolate has the same sporulation phase as the standard Bt strain (Bulla et al., 1980). The selected isolate was inoculated into a sterilized $250 \mathrm{ml}$ conical flask containing $100 \mathrm{ml}$ Nutrient Broth. The optical density measurements were taken at an interval of 5 for $120 \mathrm{~h}$. Simultaneously, the sample was also monitored to determine the start of the sporulation and complete autolysis phase.

\section{Bacillus thuringiensis Spore-Crystal Preparation}

The cultures were monitored for the formation of the endospores and the parasporal bodies under the phase contrast microscope, which indicates that complete autolysis, had occurred. An aliquot of $10 \mathrm{ml}$ of the Nutrient Broth containing the lysed bacterial cells was transferred into a $50 \mathrm{ml}$ Beckmans centrifuge tube. The protein was isolated from other cellular material by centrifugation at 10, $000 \mathrm{rpm}$ at $4^{\circ} \mathrm{C}$ for $15 \mathrm{~min}$. The supernatant was discarded and the pellet was washed a further two times in sterile distilled water to remove cell debris and secretory products, then resuspended in $1 \mathrm{ml}$ of sterile distilled water.

\section{Protein purity checking}

The purity of protein was analyzed using UV spectrophotometer. Both the optical density of 260 and $280 \mathrm{~nm}$ was taken. The ratios of absorbance at 280 over $260 \mathrm{~nm}$ were calculated. Ratio values of approximately 1.8 to 2.0 were considered as pure protein samples. Protein Quantification was carried out using Bradford Method (Bradford, 1976).

\section{SDS-PAGE analysis}

SDS-PAGE of $B$. thuringiensis proteins was performed as described by Laemmli (1970), using $10 \%$ separating and $4 \%$ stacking gels to determine the molecular weight of the proteins. The presence of the Cry and Cyt protein bands were visualized using the Digital Gel Documentation System. The molecular masses of the proteins were estimated by comparison with Bovine Serum Albumin (66 kDa) protein subjected to SDS-PAGE.

\section{Strain maintenance}

Isolates were inoculated into $50 \mathrm{ml}$ Nutrient Broth and incubated at room temperature in an incubator rotating at $250 \mathrm{rpm}$. Each culture was examined periodically by phase-contrast microscopy until the population had lysed, releasing spores and crystals. Then $1 \mathrm{ml}$ aliquot was transferred into a cryogenic vial and glycerol was added to a concentration of $60 \%$. The suspensions were vortexed, labeled and stored at $-80^{\circ} \mathrm{C}$.

\section{RESULTS}

About 85 colonies having the typical Bacillus-like characteristics were selected. These colonies have white to off-white colour, slightly raised elevation and regular margins (Mohammedi et al., 2006). The morphological identification of Bacillus can be seen in Figure 1. These colonies were then isolation and sub-cultured into fresh plates.

Since the genus Bacillus consists of rod-shaped and Gram-positive confirmed bacteria, therefore Gram staining was conducted to eliminate all other bacteria that do not have these two features. All rod-shaped, Gram positive bacteria, which appeared blue or violet under the light microscope, were selected, and the remaining isolates that did not exhibit such description were discarded. During their growth cycle, strains of Bacillus grow as undifferentiated rod-shaped vegetative cells (Figure 2). Total of 35 colonies were selected and subjected to phase contrast microscopy.

Colonies which were Gram positive rods were further analysed by phase-contrast microscope to screen for the presence of endospore and parasporal body in order to distinguish $B$. thuringiensis from other Bacillus groups (Figure 3). Phase contrast microscopy was done after 50 and $90 \mathrm{~h}$ to ensure the presence of rod-shaped vegetative cells and to screen for the presence of parasporal bodies, respectively. The colonies were microscopically examined and those having visible parasporal inclusions were classified as $B$. thuringiensis (Bernhard et al., 1997), and selected for further characterization. In total 8 colonies were identified to be $B$. thuringiensis by using this method.

All the 35 isolates were further stained with Coomassie Brilliant Blue and viewed under Phase Contrast Microscopy. About 8 samples were selected and these isolates were confirmed as $\mathrm{Bt}$ as the presence of parasporal bodies was immediate and strikingly evident by the presence of numerous dark-blue staining objects (Figures 4, 5 and 6). The use of Coomassie Brilliant Blue stain relatively allowed a quick and high throughput assessment of the 8 isolates. Crystal morphology of Bt can give information about target insect spectra (Maeda et al., 2000). Therefore, the isolates were examined for crystal morphology and two different types of crystal shapes were observed in the 8 isolates, in which they are bipyramidal and round or oval shapes.

Out of the 8 strains isolated, isolate S2 was used to 

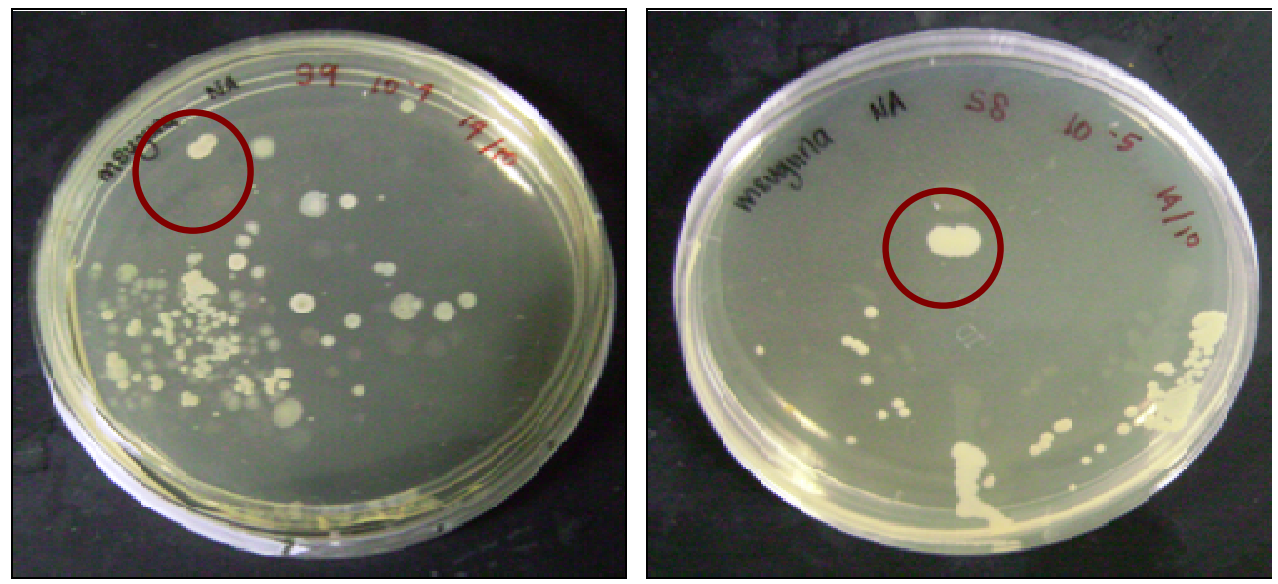

Figure 1. Colony morphology: White to creamy colonies indicates that they are possible Bacillus colonies.

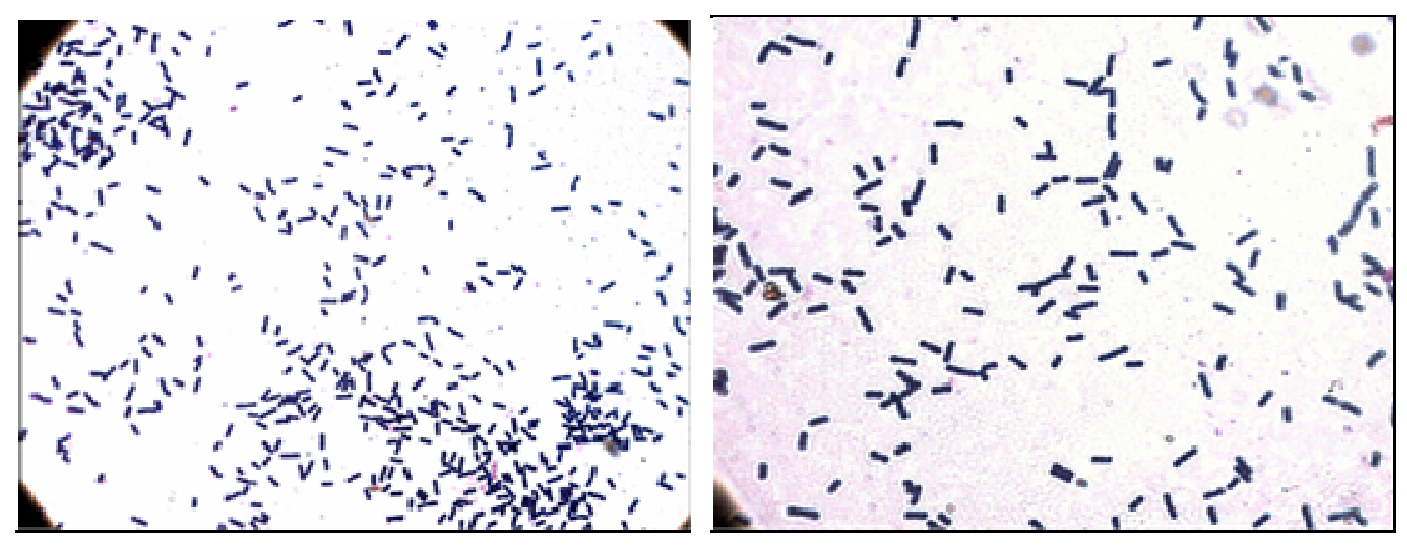

Figure 2. (A) Gram-positive (blue stained), rod-shaped Bacillus at $400 \mathrm{X}$ magnifications. The cells are in vegetative form, as they appear to be long and thin rods; (B) Bacillus (thick and short) can be observed in the figure above at $400 \mathrm{X}$ magnifications.

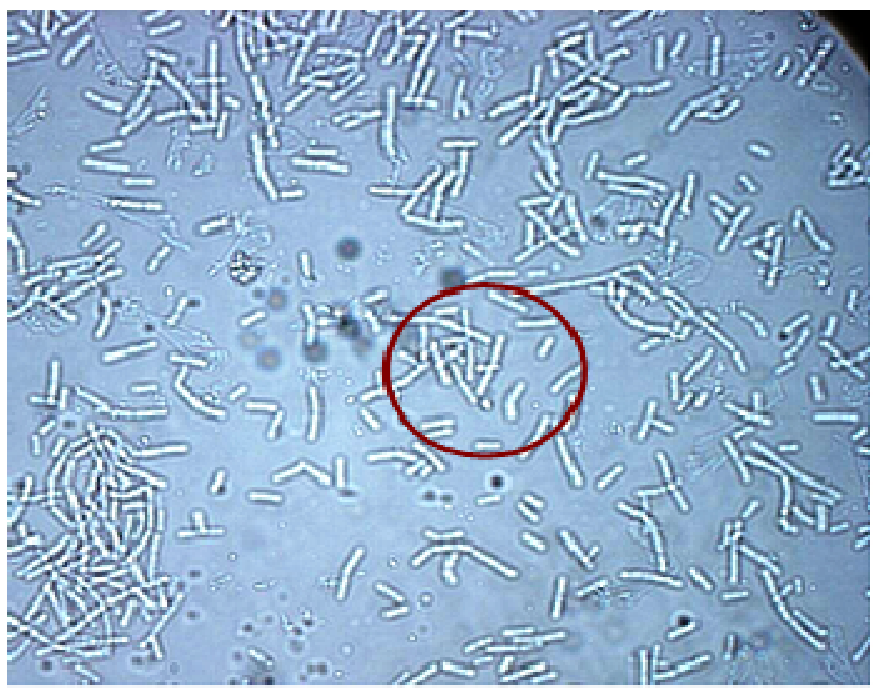

Figure 3. The cells in the dark red circle represent the vegetative form of Bacillus cells at $1000 \mathrm{X}$ magnification.

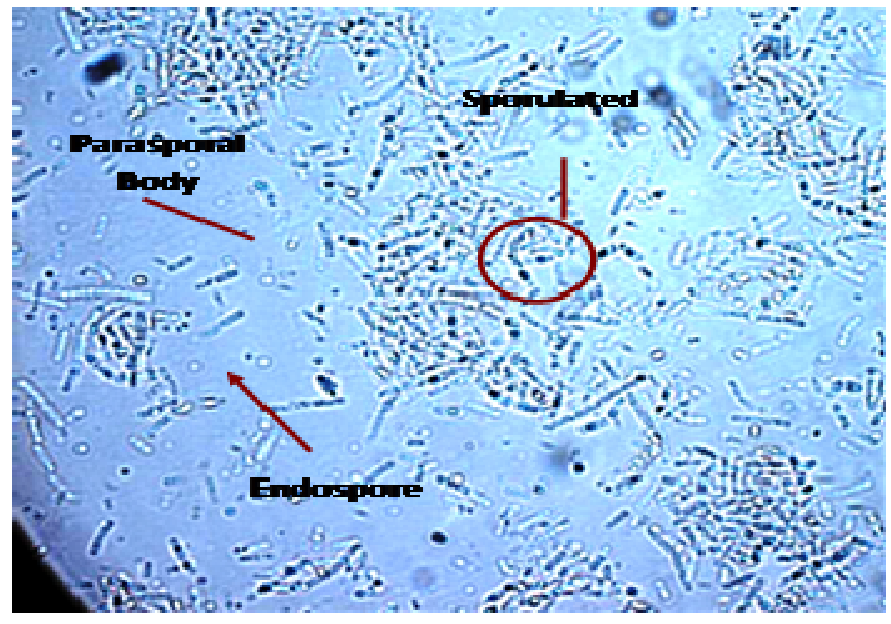

Figure 4. The sporulated forms of Bacillus were shown in the dark red circle. The clear and bright portion is the spore whereas the parasporal body appears as dark blue, when observed under 1000 $\mathrm{X}$ magnification. 

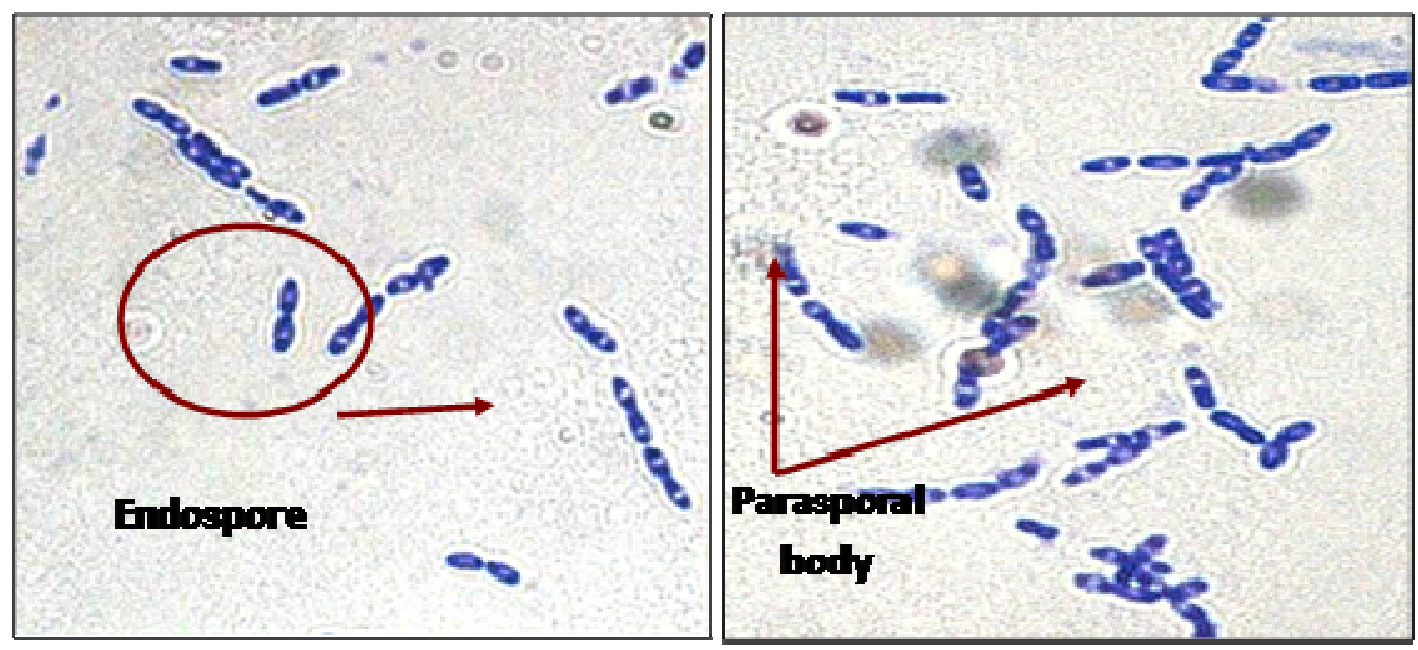

Figure 5. Phase contrast microscopy of sporulated cells (in dark red circle), endospore formation and dark blue stained parasporal bodies (1000 x magnification).
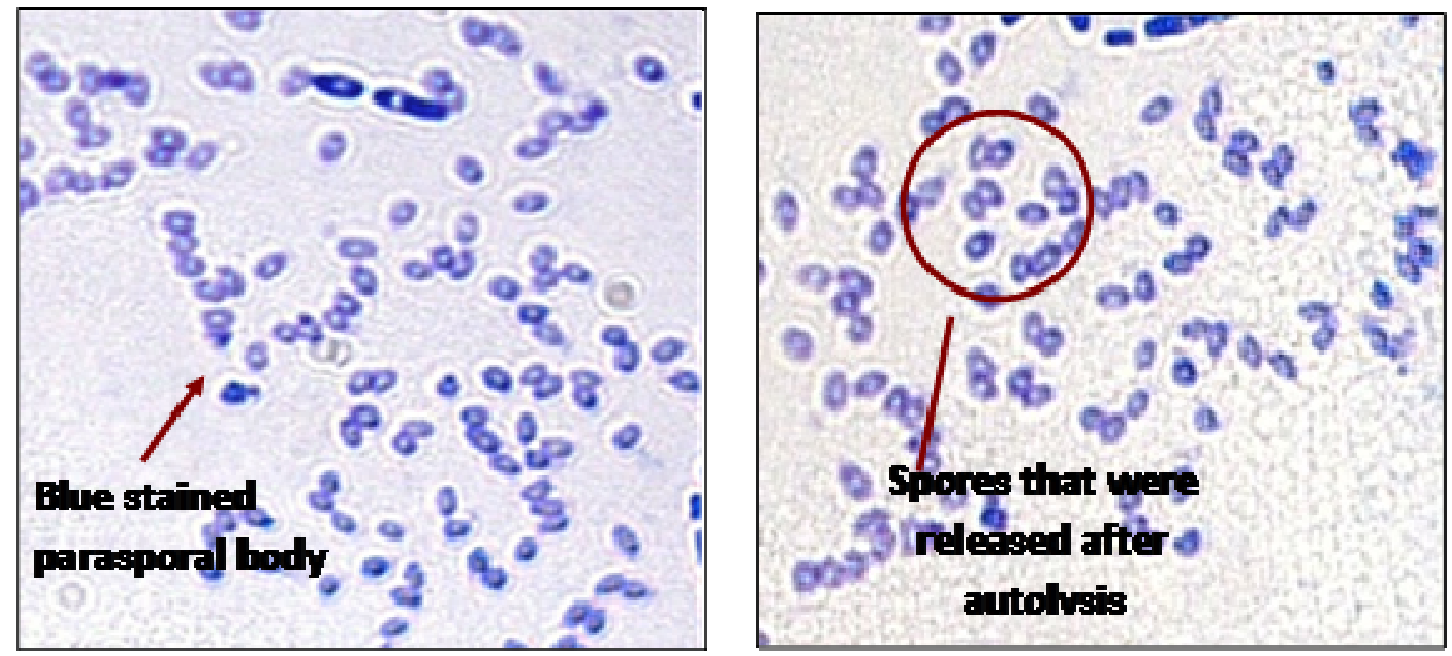

Figure 6. Phase contrast microscopy shows spores and crystals that were released into medium after autolysis (1000 x magnification).

generate a growth curve. Samples were taken at an interval at every 5 for $120 \mathrm{~h}$ for optical density measurements and the setup of sporulation was monitored by phase contrast microscopy simultaneously (Figure 7). This is to ensure the start of the sporulation process in tandem with the sporulation period. The growth curve generated below shows that the isolate starts to sporulate approximately at the $90 \mathrm{~h}$ after incubation in Nutrient Broth. Normally, a typical Bt strain undergoes the sporulation period approximately at about 90-92 $\mathrm{h}$ (4 days) after incubation (Bulla et al., 1980). Thus, it can be confirmed that this particular strain have similar sporulation phase as the typical Bt strain.

The SDS-PAGE analysis of the protein preparations showed strains with $\delta$-endotoxin ranging from 70 to 150
$\mathrm{kDa}$, representing the Cry proteins and 18-40 kDa representing the Cyt proteins. Bt strains produce common patterns of molecular weights (MW) which ranges from 20 to $140 \mathrm{kDa}$. This can be observed in Figure 8 . Six strains presented the typical molecular weights of $\mathrm{Bt}$ strains and this can be observed in Lanes 2-7 with their molecular weights ranging from $18-150 \mathrm{kDa}$. However, samples in Lanes 1 and 8 revealed only two pronounced low molecular weight protein bands of approximately 36 and $33 \mathrm{kDa}$ respectively.

\section{DISCUSSION}

In this study, Bt occurrence was examined in chicken 


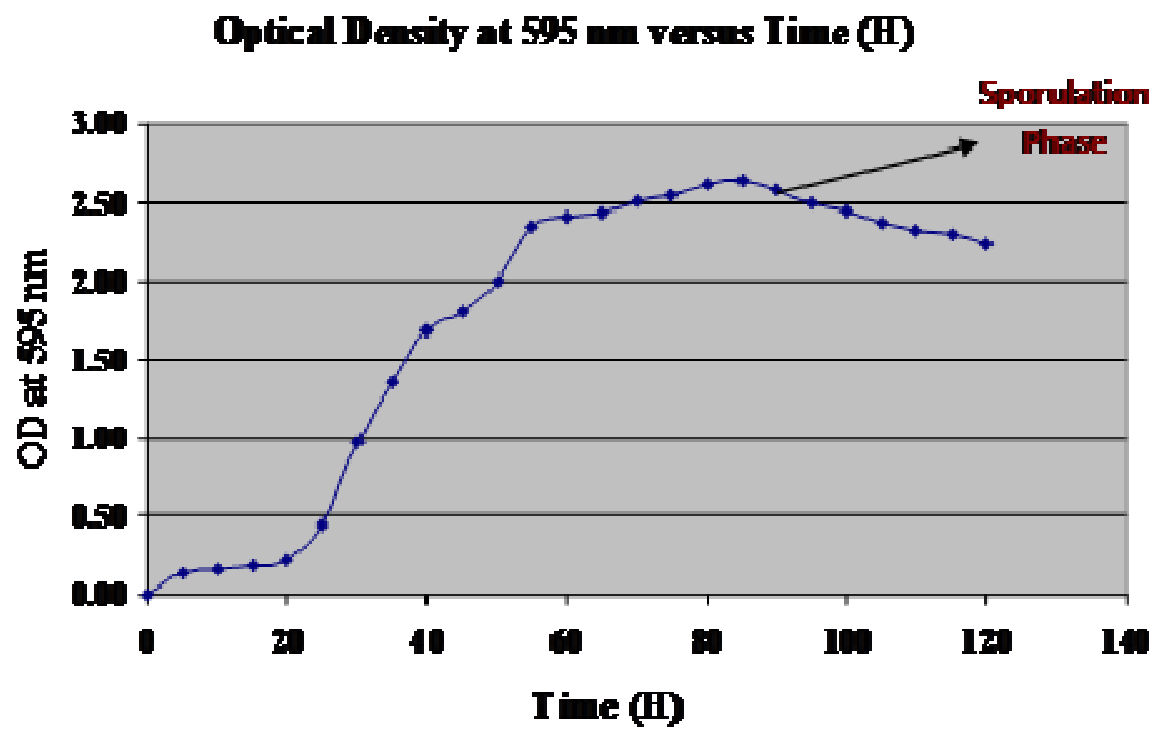

Figure 7. Growth curve of Bacillus thuringiensis isolate S2 shows that the sporulation phase occurs at $90 \mathrm{~h}$ after incubation

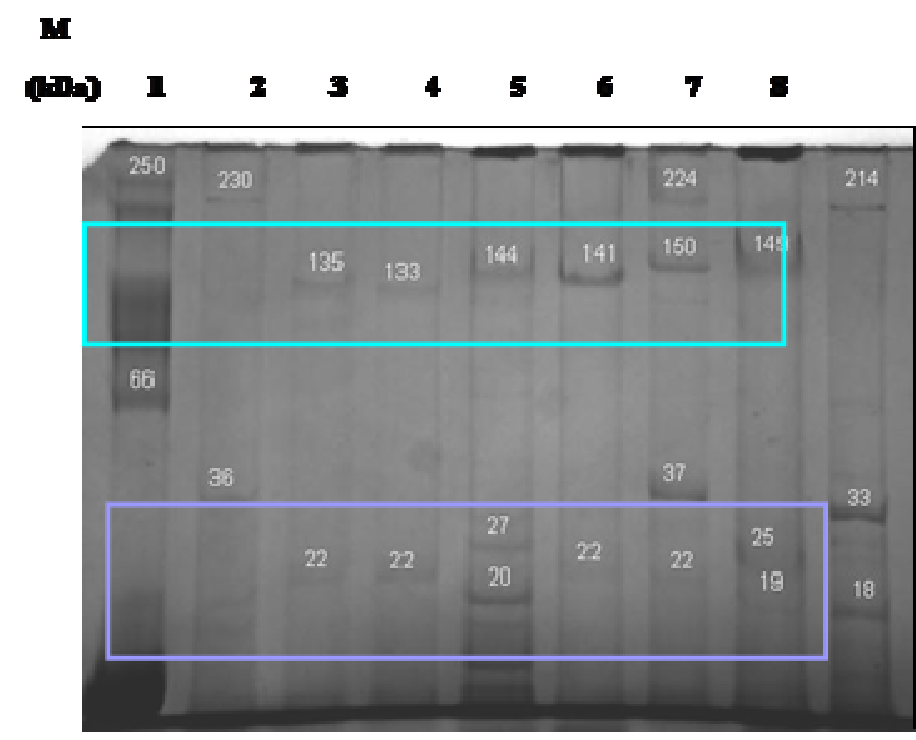

Figure 8. Cry and Cyt protein SDS-PAGE of eight Bacillus thuringiensis strains. Lane 1: Sample 50 showing a band of $36 \mathrm{kDa}$, lane 2 and 3: Samples 53 and 51 respectively, showing bands ranging between 22 and $135 \mathrm{kDa}$, lane 4 : Sample 18 with three bands of 20, 27 and $144 \mathrm{kDa}$, lane 5: Sample 20 consists of two bands of 22 and $141 \mathrm{kDa}$, lane 6: Sample 52 showing a low molecular weight band of $22 \mathrm{kDa}$ and two prominent bands of 37 and $150 \mathrm{kDa}$, lane 7: Sample 2 with a low molecular weight protein of $19 \mathrm{kDa}$ and two other bands of 25 and $149 \mathrm{kDa}$, and lane 8 : Sample 54 showing a relatively low molecular weight band of 18 and $33 \mathrm{kDa}$

manure samples in which 8 strains were isolated successfully. The designated protocol uses heat treatments, in which it selectively eliminates all the non- spore forming bacteria and the vegetative cells. Thus only endospore forming bacteria which grow on Nutrient Agar plates were subjected to further characterization. Eighty-five colonies were isolated mainly based on morphological characteristics of Bacillus group. These colonies have white to off white colour, slightly raised elevation and regular margin (Smith and Couche, 1997). Gram staining technique further eliminates the entire Gram negative isolates, thus only Gram positive rodshaped isolates were selected. A total of 35 isolates were identified and further monitored for the presence of endospores and parasporal bodies. Prior to this, the isolates were inoculated into Nutrient Broth and incubated at room temperature at $250 \mathrm{rpm}$. Isolates were harvested separately at both 50 and $90 \mathrm{~h}$ in order to monitor the vegetative cells and the formation of sporulated cells, and thereafter viewed under the phase contrast microscope. The capped spores can be observed in 8 of the isolates.

All the 8 isolates were then subjected to Coomassie Brilliant Blue staining technique in which the technique allows high-throughput evaluation of the presence of crystals (Rampersad et al., 2002).

Even though the remaining 27 other isolates had Bt-like spore and colony morphology, they did not showed any crystal formation and thus were eliminated. The high contrast of the stain allowed identifying the relatively small sized crystals or the small number of cap-like structures. The presence of parasporal bodies was immediate and strikingly evident by the presence of numerous dark-blue staining objects and thus allowed the morphological identification the parasporal bodies. Ovalshaped / round and bipyramidal-shaped parasporal bodies were examined under the phase contrast 
microscopy. This confirms that those isolates were Bacillus thuringiensis. Morphological characters of crystals can provide an overall idea of the target insect specificity (Maeda et al., 2000) and thus it can be said that these isolates may be toxic to both Lepidopteran and Dipteran larvae (Hofte and Whiteley, 1989). One of the isolates, S2, was chosen to construct the growth curve based on the absorbance at $595 \mathrm{~nm}$ at an interval of 5 for $120 \mathrm{~h}$. Concurrently, the cells were monitored for the presence of the endospores and parasporal bodies, which indicates the start of the sporulation phase. It was observed that the strain sporulated after $90 \mathrm{~h}$ of incubation in Nutrient Broth at 250 rpm agitation. The growth curve of the isolated strain was cross-referred to the growth curve of the standard Bt strain, as described in Bulla et al. (1980). These two strains have similar sporulation period, and thus it can be confirmed that the strain Bacillus thuringiensis.

Analysis of SDS-PAGE (13) further reveals that these strains have the Cytolytic (Cyt) proteins and the Crystal (Cry) proteins. However, only 6 strains (S53, S51, S18, S20, S2 and S54) have both of the proteins. The protein profile of these strains ranges from 133-150kDa which corresponds to the Cry proteins, and 18 to $27 \mathrm{kDa}$ proteins which correspond to the Cyt proteins. The diversity of molecular weights of the $\delta$-endotoxins observed in the SDS-PAGE analyses, suggest that there are strains expressing two different Cry proteins that could be toxic against Lepidopternas and Dipterans, encoded by cryl $(140 \mathrm{kDa})$ and crylV (135 kDa) genes respectively (Schnepf et al., 1998). Additionally, these two proteins could also be described as having toxicity against Coleopterans, as the anticoleopteran toxicity ranges between 130 and $140 \mathrm{kDa}$, encoded by cry VII and crylB respectively (Arrieta et al., 2004). These 6 strains also show the presence of Cyt proteins in the protein profile range of 18 to $27 \mathrm{kDa}$ range in which it can augment the Cry toxins, in order to enhance the effectiveness of insect control. However, the analysis revealed only one pronounced low molecular weight protein of approximately $36 \mathrm{kDa}$ for $\mathrm{S} 50$ and two major proteins, also low molecular weight, of approximately 18 and $33 \mathrm{kDa}$ for S54. The protein profile of these two isolates corresponds to the cytolytic (Cyt) proteins. Cyt toxins are hemolytic and cytolytic in vitro and are specifically active against Dipteran larvae in vivo (Knowles et al., 1989; Yu et al., 1991). The absence of Cry proteins however can be seen in these two isolates. Given the variability of insecticidal proteins described to date, the isolation and characterization of various new subspecies of $B$. thuringiensis could contribute to the discovery of very effective biopesticide with higher insecticidal activities and broader host range against insect pests especially in the sectors of agriculture and forestry, and vectors of medically important diseases of human beings and other animals in Malaysia. In conclusion, this study contributes to the establishment of $\mathrm{Bt}$ native strains that are present in various environments in
Malaysia.

\section{REFERENCES}

Aronson Al, Shai Y (2001). Why Bacillus thuringiensis insecticidal toxins are so effective: Unique features of their mode of action. FEMS. Microbiol. Lett., 195:1-8.

Arrieta G, Hernández A, Espinoza A M (2004). Diversity of Bacillus thuringiensis strains isolated from coffee plantations infested with the coffee berry borer Hypothenemus hampei. Rev. Biol. Trop., 52(3): 757-764.

Bradford MM (1976). A rapid and sensitive method for the quantitation of microgramquantities of protein-dye binding. Anal. Biochem., 72: 248-254.

Bernhard K, Jarret P, Meadows M, Butt J, Ellis DJ, Roberts G.M, Pauli S, Rodgers P, Burges HG (1997). Natural isolates of Bacillus thuringiensis: Worlwide Distribution, Characterization, and Activity against Insects Pests. J. Invertebr. Pathol., 70:59-68.

Bulla LA, Bechtel DB, Kramer KJ, Shetna YL, Aronson AI, Fitz-James PC (1980) Ultrastructure, physiology and biochemistry of Bacillus thuringiensis. Crit. Rev. Microbiol., 8:147-204.

Crickmore N (2006) Beyond the spore - past and future developments of Bacillus thuringiensis as a biopesticide. J. App. Microbiol., 101(3):616-619.

Ghelardi E, Celandroni F, Salvetti S, Fiscarelli E, Senesi S (2007) Bacillus thuringiensis: Pulmonary infection, critical role for bacterial membrane-damaging toxins and host neutrophils. Microb. Infect., 9(5): 591-598.

Hofte H, Whiteley, H.R. (1989) Insecticidal crystal proteins of Bacillus thuringiensis. Microbiol. Rev. 53: 242-255

Huang TK, Wang PM, Wu WT (2001). Cultivation of Bacillus thuringiensis in an airlift reactor with wire mesh draft tubes. Biochem. Eng., J. 7:35-39.

Konecka E, Kaznowski A, Ziemnicka J, Ziemnicki K. (2006). Molecular and phenotypic characterization of Bacillus thuringiensis isolated during epizootics in Cydra pomonella L. J. Inverteb. Pathol., 94: 5663.

Lacey LA, Frutos R, Kaya HK, Vale P (2001). Insect pathogens as biological control agents: Do they have a future? Biol. Control., 21: 230-248

Laemlli UK (1970). Cleavage of structural proteins during the assembly of the head of bacteriophage T4. Nat. 227:680-685.

Maeda M, Mizuki E, Nakamura Y, Hatano T, Ohba M (2000) Recovery of Bacillus thuringiensis from marine sediments of Japan. Curr. Microbiol., 40: 413-422.

Mohammedi S, Balasubramanian S, Yan S, Tyagi RD, Valero JR (2006). Molecular screening of Bacillus thuringiensis strains from wastewater sludge for biopesticide production. Process. Biochem., 41: 829-835.

Moraga E, Tovar E, Garcia P, Alvarez C (2004) Isolation, geographical diversity and insecticidal activity of Bacillus thuringiensis from soil in Spain. Microbiol. Res., 159: 59-71.

Rampersad J, Ammons D (2005). A Bacillus thuringiensis isolation method utilizing a novel strain, low selection and high throughput produced a typical results. BMC. Microbiol., 5: 52.

Rampersad J, Ayub K, Ammons D (2002) Usefulness of staining parasporal bodies when screening for Bacillus thuringiensis. J. Inverteb. Pathol., 79(3): 203-204.

Schnepf E, Crickmore N, Van Rie J, Lereclus D, Baum J, Feitelson J, Zeigler DR, Dean DH (1998). Microbiol. Mol. Biol. Rev., 62(3):775806.

Smith RA, Couche GA (1997). The phylloplane as a source of Bacillus thuringiensis variants. Appl. Environ. Microbiol., 57: 311-315

Yu YM, Ohba M, Gill SS (1991) Characterization of mosquitocidal activity of Bacillus thuringiensis subsp. fukuokuensis crystal proteins. Appl. Environ. Micribiol., 57:1075-1081. 